University of Nebraska - Lincoln

DigitalCommons@University of Nebraska - Lincoln

Educational Psychology Papers and

Publications

Educational Psychology, Department of

April 2004

\title{
Perceptions of Helpfulness in Conjoint Behavioral Consultation: Congruence and Agreement between Teachers and Parents
}

\author{
Susan M. Sheridan \\ University of Nebraska-Lincoln, ssheridan2@unl.edu \\ William P. Erchul \\ North Carolina State University, william_erchul@ncsu.edu \\ Melissa S. Brown \\ University of Nebraska-Lincoln \\ Shannon E. Dowd \\ University of Nebraska-Lincoln \\ Emily D. Warnes \\ University of Nebraska-Lincoln \\ See next page for additional authors
}

Follow this and additional works at: https://digitalcommons.unl.edu/edpsychpapers

Part of the Educational Psychology Commons

Sheridan, Susan M.; Erchul, William P.; Brown, Melissa S.; Dowd, Shannon E.; Warnes, Emily D.; Marti, Diane C.; Schemm, Ariadne V.; and Eagle, John W., "Perceptions of Helpfulness in Conjoint Behavioral Consultation: Congruence and Agreement between Teachers and Parents" (2004). Educational Psychology Papers and Publications. 9.

https://digitalcommons.unl.edu/edpsychpapers/9

This Article is brought to you for free and open access by the Educational Psychology, Department of at DigitalCommons@University of Nebraska - Lincoln. It has been accepted for inclusion in Educational Psychology Papers and Publications by an authorized administrator of DigitalCommons@University of Nebraska - Lincoln. 


\section{Authors}

Susan M. Sheridan, William P. Erchul, Melissa S. Brown, Shannon E. Dowd, Emily D. Warnes, Diane C. Marti, Ariadne V. Schemm, and John W. Eagle 
Published in School Psychology Quarterly 19:2 (2004), pp. 121-140. Copyright (C 2004 American Psychological Association. Used by permission. "This article may not exactly replicate the final version published in the APA journal. It is not the copy of record." http://www.apa.org/journals/spq/

\title{
Perceptions of H elpfulness in Conjoint Behavioral Consultation: Congruence and Agreement between Teachers and Parents
}

\author{
Susan M. Sheridan \\ University of N ebraska-Lincoln \\ William P. Erchul \\ North Carolina State U niversity \\ Melissa S. Brown, Shannon E. Dowd, Emily D. Warnes, \\ Diane C. Marti, Ariadne V. Schemm, and John W. Eagle \\ University of $\mathrm{N}$ ebraska-Lincoln
}

\begin{abstract}
Conjoint behavioral consultation (CBC) can be considered a help-giving model, wherein consultants work with parents and teachers in an effort to develop constructive partnerships aimed at addressing needs of students for whom both parties share responsibility. The development of strong relationships among systems in a child's life is related to positive outcomes for children, and congruence among systems is one relationship variable that has received previous research attention. This study examined the degree to which parent and teacher perceptions of the helpfulness of the CBC consultant are congruent, and its relationship with various case outcomes. Correlational analyses suggest that parents' and teachers' perspectives of the helpfulness of the consultant are not necessarily related to each other, and as differences increase, perceptions of outcomes decrease for both parties. Research implications, limitations, and future directions are offered.
\end{abstract}

Consultation research has evolved over several years to encompass evaluations of outcomes, processes, and social validity (Sheridan, Welch, \& Orme, 1996). Behavior-

Research reported herein was supported in part by grants awarded to the first author by the U.S. Department of Education, Office of Special Education and Rehabilitative Services. The opinions expressed herein are those of the authors and should not be interpreted to reflect those of the granting agency.

Portions of this article were presented at the annual conference of the American Psychological Association, Chicago, IL, August, 2002.

Address correspondence to Susan M. Sheridan, 239 Teachers College Hall, Department of Educational Psychology, University of Nebraska-Lincoln, Lincoln, NE 68588-0345; E-mail: ssherida@unlserve.unl.edu. 
al consultation and its variants (e.g., conjoint behavioral consultation [CBC]; Sheridan, Kratochwill, \& Bergan, 1996) have been demonstrated to be effective and acceptable across a range of target behaviors and participant samples (e.g., Colton \& Sheridan, 1998; Sheridan, Eagle, Cowan, \& Mickelson, 2001). Perceptions of the degree to which the process of CBC is acceptable have been explored (Sheridan \& Steck, 1995), as have assessments of individual participants' perspectives of various outcomes (e.g., Galloway \& Sheridan, 1994; Weiner, Sheridan, \& Jenson, 1998). Some process, process-outcome, and social power studies have begun to shed light on relational elements in consultation and CBC (e.g., Erchul, Raven, \& Whichard, 2001; Erchul et al., 1999). However, although research is beginning to emerge, more investigation is necessary. Specifically, relationships among the perceptions of parents and teachers engaged in $\mathrm{CBC}$ interactions have not been explored, nor have key constructs related to $\mathrm{CBC}$ as a model to facilitate a helping interaction.

For the purposes of this study, we conceptualize conjoint behavioral consultation as a help-giving model aimed at assisting parents and teachers to develop, implement, and evaluate plans for student success. We contend that congruence in parents' and teachers' ratings of consultant helpfulness, and the extent to which parents and teachers agree about elements of helpfulness, may be related to a variety of objective and subjective case outcomes. A heuristic framework elucidating the connections between the principles of $\mathrm{CBC}$, characteristics of helpfulness, and measurement considerations is presented in Table 1.

\section{CONJO INT BEHAVIO RAL CONSULTATION}

CBC is a model of service delivery that attempts to develop effective partnerships among parents, educators, and other support providers. It is defined as "a structured, indirect form of service-delivery, in which parents and teachers are joined to work together to address the academic, social, or behavioral needs of an individual for whom both parties bear some responsibility" (Sheridan \& Kratochwill, 1992, p. 122). The objectives of $\mathrm{CBC}$ are to address child-related behavioral, social, or academic concerns; and strengthen the connections between home and school systems (Sheridan et al., 1996). One possible outcome of CBC is the development of constructive relationships whereby consistency and congruence among systems are developed.

By adopting an ecological-systems perspective (Bronfenbrenner, 1979; Sheridan et al., 1996), CBC acknowledges that children function within and across various systems in their environments - the two primary systems in children's lives being the home and school. CBC is also based in behavioral theory, as children's behaviors are viewed as a function of the environment in which they occur. CBC consultants approach children's needs and consultees' concerns by emphasizing observable behaviors and helping to set clear, specific, and observable behavioral goals based on objectively collected information (Sheridan et al., 1996). 
TABLE 1. Correspondence between Helpfulness, Conjoint Behavioral Consultation, and their Measurement

\begin{tabular}{|c|c|c|}
\hline $\begin{array}{l}\text { Characteristics of Helpfulness } \\
\text { (Dunst \&Trivette, 1994) }\end{array}$ & $\begin{array}{c}\text { Principles of Conjoint } \\
\text { Behavioral Consultation } \\
\text { (Sheridan, Kratochwill, } \\
\text { \& Bergan, 1996) }\end{array}$ & $\begin{array}{l}\text { Items from the Consultant } \\
\text { Evaluation Form } \\
\text { (CEF; Erchul, 1987) }\end{array}$ \\
\hline $\begin{array}{l}\text { - Employs active and reflective } \\
\text { listening. } \\
\text { - Helps clients clarify concems } \\
\text { and needs } \\
\text { - Pro-offers help in response } \\
\text { to help-seeker neods } \\
\text { - Offers help that is normative } \\
\text { - Offers help that is congruent } \\
\text { and matches the help-seeker's } \\
\text { appraisal of noeds }\end{array}$ & $\begin{array}{l}\text { Responds to Clients' Needs } \\
\text { - Consultants offer help rather } \\
\text { than help being requested } \\
\text { - Consultants provide help that is } \\
\text { congruent with consultees' needs } \\
\text { - Consultants do not determine } \\
\text { target behaviors and/or } \\
\text { interventions } \\
\text { - Data collection and interventions } \\
\text { based on what works in } \\
\text { consultees'environments }\end{array}$ & $\begin{array}{l}\text { - The consultant was } \\
\text { generally helpful. } \\
\text { - The consultant offered } \\
\text { useful information. } \\
\text { - The consultant was a } \\
\text { good listener. } \\
\text { - The consultant fit well } \\
\text { into the school or } \\
\text { agency's environment. } \\
\text { - The consultant's ideas as } \\
\text { to the primary gcals of } \\
\text { schools or agencies were } \\
\text { similar to my own ideas. } \\
\text { - The consultant was able } \\
\text { to offer assistance without } \\
\text { completely "taking over" } \\
\text { the management of the } \\
\text { problem. }\end{array}$ \\
\hline $\begin{array}{l}\text { - Promotes acquisition of } \\
\text { competencies to meet needs, } \\
\text { solve problems, and achieve } \\
\text { aspirations } \\
\text { - Allows locus of decision } \\
\text { making to rest with the } \\
\text { help-seeker }\end{array}$ & $\begin{array}{l}\text { - Consultants focus on existing } \\
\text { skills, strengths, and competencies } \\
\text { - CBC process creates opportunities } \\
\text { for families to acquire knowledge } \\
\text { to manage concems (e.g., problem } \\
\text { solving approach, data-based } \\
\text { decision making strategies, } \\
\text { specific interventions) } \\
\text { - Skills leamed in CBC can be } \\
\text { used for future problem solving } \\
\text { - Increased sense of self-efficacy } \\
\text { and empowerment among } \\
\text { consultees }\end{array}$ & $\begin{array}{l}\text { - The consultant helped me } \\
\text { identify useful resources. } \\
\text { - The consultant helped me } \\
\text { find ways to apply the } \\
\text { content of our discussions } \\
\text { to specific situations. } \\
\text { - The consultant helped me } \\
\text { find alternative solutions } \\
\text { to problems. }\end{array}$ \\
\hline \multicolumn{3}{|c|}{ Promotes Parmership and Collaboration among Systems } \\
\hline $\begin{array}{l}\text { Employs partnerships and } \\
\text { parent-professional } \\
\text { collaboration as the } \\
\text { mechanism for meeting } \\
\text { needs }\end{array}$ & $\begin{array}{l}\text { - CBC process involves } \\
\text { collaborative problem solving } \\
\text { - Joint responsibility among home } \\
\text { and school systems for problem } \\
\text { and problem solutions } \\
\text { - Consultees learn strategies for } \\
\text { working across systems to meet } \\
\text { needs of the child } \\
\text { - Consultants are positive and } \\
\text { proactive in their approach to } \\
\text { working with systems - focus is } \\
\text { on common goals rather than on } \\
\text { problems within systems }\end{array}$ & $\begin{array}{l}\text { - The consultant was a } \\
\text { good listener. } \\
\text { - The consultant viewed his } \\
\text { or ber role as a } \\
\text { collaborator rather than } \\
\text { an expert. } \\
\text { - The consultant } \\
\text { encouraged me to } \\
\text { consider a number of } \\
\text { points of view. }\end{array}$ \\
\hline
\end{tabular}




\section{CBC as a Model of Helpfulness}

For this study, we conceptualize $\mathrm{CBC}$ as a helping model, defined by Dunst, Trivette, Davis, and Cornwell (1994) as

an act of enabling individuals or groups to become better able to solve problems, meet needs, or achieve aspirations by promoting the acquisition of competencies that support and strengthen functioning in a way that permits a greater sense of individual or group control over its developmental course (p. 162).

These authors have described help-giving behaviors to include the areas discussed in the first column of Table 1. The characteristics of effective helping are consistent with the main principles and objectives of $\mathrm{CBC}$ and can be organized around three salient characteristics: (a) responsiveness to needs of client, (b) promotion of competency acquisition, and (c) promotion of partnership and collaboration among systems (Dunst et al., 1994). In the following sections, central principles of CBC are presented in the context of helping characteristics to elucidate the common features.

Responsiveness to clients' needs. CBC provides help that is congruent with the families' appraisals of their needs and thus addresses one of the main helping principles by its responsiveness to the needs of families. In CBC, target behaviors and interventions are determined by consultees' priorities, rather than a predetermination of needs by the consultant (Sheridan et al., 1996). The consultant facilitates the process of helping consultees select target behaviors and interventions, provides only the services requested by consultees, assures the voluntary nature of consultation (Gutkin \& Curtis, 1999), and seeks to build on consultees' sense of control for making decisions based on information and skills attained through experience with the CBC process (Dunst et al., 1994). Additionally, the design of data collection and interventions is based on what works best within consultees' home and school environments, also an essential principle of helping and family empowerment (Dunst, Trivette, \& Deal, 1988). Accepting families and teachers "where they are" (i.e., acknowledging parents' and teachers' frames of reference; Sheridan et al., 1996), ensures that consultants do not attempt to focus on the deficits of consultees, but rather on the strengths and resources they bring to the process (Dunst et al., 1994).

Promotion of competency acquisition. A primary goal of $\mathrm{CBC}$ is to increase consultees' skills and knowledge to address future problems. This is done by (a) using a structured problem solving approach, (b) implementing strategies based on databased decisions, and (c) promoting knowledge of appropriate interventions (Sheridan et al., 1996). Skill acquisition allows consultees the opportunity to be independent in addressing the current and future needs of the clients in their care. In this way, the collaborative problem solving process is modeled, and in essence, "given away" to consultees (Dunst \& Trivette, 1987; Miller, 1969). 
Promoting consultees' skills and competencies in problem solving also increases their sense of self-efficacy, an essential principle necessary for the empowerment of clients and consultees (Dunst \& Trivette, 1987; Dunst et al., 1988).

Promotion of partnership and collaboration. An overarching goal of $\mathrm{CBC}$ is the establishment of partnership and collaboration among family and school systems (Christenson \& Sheridan, 2001; Sheridan et al., 1996). Throughout consultation, home and school systems are collaboratively involved in a joint problem solving process to address common goals for children. This allows schools and families to share in decision making and adopt equal responsibility for both the concerns addressed and the solutions developed in consultation. In CBC, parents and teachers each actively participate in determining meaningful target behaviors and goals for child clients, and they are mutually involved in systematic data collection and intervention procedures. Consultees work together and remain focused on a common goal—addressing the needs of the child. With this approach, consultees learn methods for collaborating across home and school systems and establishing working partnerships.

\section{Home-School Congruence and Agreement}

In addition to the benefits associated with partnerships and mutual collaboration, educational research also suggests that the development of strong relationships among systems is related to positive outcomes for children (Chavkin \& Williams, 1988; Comer, 1980; Henderson, 1987; Pianta \& Walsh, 1996). This complex network of synchronous home-school relationships might be best captured by the term "congruence." Congruence among homes and schools affects student achievement and engagement with learning. That is, the more "in sync" schools and families are visá-vis learning and development, the better the outcomes for children (Christenson \& Sheridan, 2001).

Pianta and Walsh (1996) also highlighted the importance of congruence across systems and stressed the importance of interactions that promote shared meaning between home and school. Accordingly, a significant risk factor for youth exists when interactions do not produce shared meaning and there is a mismatch between systems in regard to education, communication, and support. Children who experience discontinuity among contexts have difficulty making transitions and are at risk for academic underachievement and mental health concerns (Phelan, Davidson, \& Yu, 1998).

Webster defines congruence as "... consistency and the quality of agreeing" (Webster, 1984). For the purpose of this article, congruence is viewed as a multidimensional relationship concerned with the degree of similarity and shared perceptions among participants. This relationship is not viewed as dichotomous; rather it is defined on a continuum from less similar to more similar. Agreement is another term used to describe a comparison of perspectives and is defined as ". . . harmony of opinion" (Webster, 1984). Within social science research, agreement is considered to be a comparison between the viewpoints of two individuals on the same issue (Laing, Phillipson, \& Lee, 
1966; McLeod \& Chaffee, 1973). Methodologically, congruence can be measured by a correlation coefficient, and agreement can be measured by the absolute value mean difference between two scores, or the sum of scores, assigned to participants' perceptions of the same issue (Erchul, Hughes, Meyers, Hickman, \& Braden, 1992).

Research suggests that a high rate of similarity (i.e., congruence) among systems is related to academic performance. In an investigation of parent educational involvement for kindergarten children in families experiencing economic stress, Hill (2001) found that parents' valuation of education and high-quality relationships between parents and teachers was positively related to kindergartners' prereading performance, and that consistency between the home and school environments may promote parental models and a home environment that enhances early reading. Similarly, an earlier study by Hansen (1986) revealed that congruence among homes and schools was associated with significant improvement in academic achievement and that children's grades declined as a function of increased discontinuity in the interactions between home and school.

Congruence/agreement with respect to views on service delivery has also been investigated. Family members and professionals report a high degree of congruence in behaviors that are "family-centered," including positiveness, support, flexibility, responsiveness, encouragement, and friendliness (McWilliam, Maxwell, \& Sloper, 1999). In the school consultation literature, agreement has been examined by Erchul et al. (1992). Looking at consultants' and consultees' perceptions of the same phenomena (e.g., consultant expertise), these researchers found that the more consultants and consultees agree on their respective roles, as well as the process and goals of consultation, the more positive are outcomes of consultation. Specifically, agreement was linked to subjective (i.e., consultee self-reported) outcomes related to the benefits of consultation, consul-tee competence, client improvement, and consultant effectiveness.

Consultation research also suggests that parents and teachers hold similar perspectives regarding the acceptability of behavioral consultation. For example, Freer and Watson (1999) found parents and teachers reported that conjoint behavioral consultation is the most preferred consultation approach for academic, behavioral, and social/emotional problems. However, this line of research has been conducted using survey methodology, assessing acceptability based on its hypothetical (versus actual) use. To date, no study has investigated the degree to which parents and teachers hold congruent beliefs about what is helpful, and how their agreement (or lack thereof) affects consultation outcomes.

Promoting linkages among the home and school systems using effective "helpgiving" strategies is central to the CBC model. Along these lines, the Consultant Evaluation Form (CEF; Erchul, 1987) is an instrument utilized within consultation to assess the effectiveness of a consultant. An evaluation of the items on the CEF suggests a strong relationship between its 12 items and the "help-giving" strategies identified 
in the literature (Dunst et al., 1994). In addition, the principles associated with the practice of CBC correspond well to both the CEF and "help-giving" strategies (see Table 1).

\section{Purpose and Hypotheses}

Although congruence between home and school contexts is important, research has not investigated the congruence between parents' and teachers' perceptions of helpfulness. Further, the effects of congruence among systems on objective and subjective case outcomes in $\mathrm{CBC}$ are not known. The purposes of this exploratory study were to assess (a) the degree to which parents' and teachers' perceptions of the helpfulness of the $\mathrm{CBC}$ consultant are congruent, and (b) the relationship between parent and teacher agreement on measures of social validity (i.e., perceived case outcomes) and behavioral outcomes (i.e., effect sizes). It was expected that agreement between parents and teachers would be positively related to objective (i.e., behavioral) and subjective (i.e., social validity) case outcomes. Alternatively, it was hypothesized that as agreement between parents' and teachers' ratings of the consultant's helpfulness decreased, behavioral outcomes would diminish, and subjective perceptions of the acceptability and effectiveness of the process would decrease. Because the data were collected in the context of naturalistic school-based cases, many controls to internal and external validity were not possible. Thus, this study is considered exploratory and descriptive in relation to its assessment of congruence and agreement, and their relationships to outcomes for children.

\section{METHOD}

This study represents a subset of a larger, 5-year CBC study conducted in two locations. One setting was an urban western city (Salt Lake City, UT) and the other was a suburban midwestern city (Lincoln, NE). Methods and results of the larger study are described elsewhere (Sheridan, Eagle et al., 2001), and readers are referred to this source for details regarding operational and methodological procedures.

\section{Participants}

Child-clients. Participants were selected through a variety of procedures depending on specific school location and administrative preferences. In the majority of cases, project staff met with school psychologists, principals, and/or special education coordinators to discuss the $\mathrm{CBC}$ process and possible referral procedures. In the majority of cases, the school psychologist or a team of specialists in a school building developed a referral list. One school representative (e.g., teacher, special educator) contacted parents and obtained their agreement to discuss concerns with a $\mathrm{CBC}$ consultant prior 
to formal referral. Upon verbal agreement, the $\mathrm{CBC}$ consultant then contacted parents and described the procedures in greater detail. Formal (i.e., written) consent to participate was obtained from parents and teachers at the first joint meeting.

The present study included 118 child-clients who ranged in age from five to 15 years $(M=9.38)$. Seventy-two percent were male. The mean grade of clients was 3.9 (range $=$ kindergarten through grade nine). Fifty-five percent of students in the sample were identified with a psychiatric or psychological disorder (e.g., learning disability, behavioral disorder, Attention-Deficit/Hyperactivity Disorder). Thirty-nine percent of the clients were considered culturally diverse on one or more variables. Specifically, $12.4 \%$ had only one parent living at home, $21.3 \%$ were nonwhite, $17.1 \%$ were living in poverty conditions, $9.3 \%$ had mothers who had not completed high school, and $5.7 \%$ spoke a language other than English in the home. Collectively, $24.6 \%$ of the clients reflected one form of diversity; $13.9 \%$ demonstrated two or more.

Parents. One hundred and thirty-seven parents participated in this study. Of these, $74 \%$ were female. The mean age of parents was 39.09 (range $=22-73 ; S D=8.05$ ). Sixty-two percent of parents reported less than a bachelor's degree as their highest educational level. Twenty-nine percent had earned a bachelor's degree, and 9\% held a master's or doctoral degree. Eighty-eight percent of parents were Caucasian.

Teachers. One hundred and four female and 18 male teachers were involved in the study. The mean age of teachers was 39.05 (range $=22$ to 57; $S D=9.53$ ). Eighty-nine percent of the teachers taught in general education classrooms; $11 \%$ were responsible for providing instruction in special education settings. Sixty-five percent of teachers listed a bachelor's degree as their highest degree earned; 35\%, a master's or doctoral degree. Of the teachers, 95\% were Caucasian.

Consultants. Consultants in the present study were 53 graduate students in school psychology programs in major western or midwestern universities. Eighty-one percent were female and $84.9 \%$ were Caucasian. The mean age of consultants was 28.42 (range $=22$ to $53 ; S D=6.50$ ). Fifty-one percent of consultants were in a doctoral program and had previously earned a master's degree. The remaining $49 \%$ were in a master's program and held a bachelor's degree at the time of the study.

\section{Settings}

This study took place in two states across two regions of the country (one in the intermountain west and one in the midwest). Forty-three schools spanning urban, rural, and suburban areas were included. The majority of schools were public; however, some parochial (Catholic) schools were involved. Similarly, the majority of cases were conducted in elementary schools, although a small number of cases were also completed in middle and high school settings. CBC interviews were conducted in schools, and generally in the classrooms of participating teachers. Interventions were implemented in the homes and schools of students who were the focus of consultation services. 


\section{Measures}

Consultant Evaluation Form. The Consultant Evaluation Form (CEF; Erchul, 1987) was used to assess teacher and parent satisfaction with CBC services. The CEF is a 12 -item instrument that uses a 7-point Likert scale to measure the degree to which consultees find consultants to be helpful. Its items are rated on a 7-point scale, with 1 indicating strong disagreement (reflecting low satisfaction/ helpfulness), and 7 indicating strong agreement (reflecting high satisfaction/ helpfulness). CEF total scores can range from 12 to 84, and 11 of the scale's items may be seen in the right column of Table 1. Research using the CEF has yielded relatively high internal consistency estimates, with mean coefficient alphas of .94 to .95 for samples consisting largely of teacher respondents (Erchul, 1987; Erchul \& Chewning, 1990; Erchul, Covington, Hughes, \& Meyers, 1995). More recently, Sheridan, Eagle et al. (2001) reported internal consistencies of .83 for a teacher sample $(n=56)$ and .89 for a parent sample $(n=53)$. In the current study, parents and teachers completed the CEF at the end of the formal consultation relationship (i.e., following the final $\mathrm{CBC}$ interview). Absolute differences were computed by subtracting one consultee's total CEF score from the other's (within the same CBC triad), and the resulting absolute difference was used as an indicator of "agreement."

Direct observations of behavior change. Direct observations of clients' (i.e., students') target behaviors were conducted by parents and teachers. Data collection forms (i.e., "Behavioral Records") were provided to consultees to (a) standardize the observational procedures, (b) provide an opportunity to train consul-tees in data collection procedures, and (c) encourage a permanent record of data. In some situations, the target behavior was defined in terms that generated a permanent product (e.g., homework completion). Direct behavioral measures were collected continuously by parents and teachers throughout all experimental phases (i.e., baseline, treatment, follow-up). No reliability data are available for direct outcome measures.

Effect sizes for individual (single-subject) cases were computed based on behavioral data collected by teachers and parents. A "no assumptions" approach (Busk \& Serlin, 1992) that computes effects without assumptions regarding population distributions or homogeneity of variance was used. With this approach, the difference in phase means within a given case is divided by the standard deviation of the baseline, which produces a quantitative index of treatment effects. Effect sizes of +1 or more indicate that the effect size is similar to one or more standard deviation units above the expected baseline mean. Because effect sizes are calculated based on the standard deviation of the baseline phase, behaviors that display a great degree of baseline variability result in lowered effect sizes.

Perceptions of efficacy. Consultees' perceptions of the efficacy of $\mathrm{CBC}$ in addressing the target concerns were assessed via a form of social validation known as subjective evaluation (Kazdin, 1977), which involves assessing the perceptions of be- 
havior change and improvement of the target child by individuals in the child's natural environment. Two instruments were used to elicit consultee perceptions of outcomes. First, parents' and teachers' perceptions of CBC efficacy were assessed on a revised version of the Behavior Intervention Rating System - Revised (BIRS; Von Brock $\&$ Elliott, 1987). The BIRS consists of 24 items rated on a 6-point Likert scale. Factor analysis of the BIRS has yielded three factors: Acceptability, Effectiveness, and Time to Effect (Elliott \& Von Brock Treuting, 1991). In a study assessing the reliability and construct validity of the BIRS, Von Brock and Elliott (1987) reported alpha coefficients of .97 for the total scale, and $.97, .92$, and .87 for the Acceptability, Effectiveness, and Time to Effect factors, respectively. In a sample reporting on outcomes in CBC, Sheridan, Eagle et al. (2001) noted alpha coefficients of .95 for teachers and .93 for parents, based on a revised version of the BIRS adapted for use in consultation. These researchers reported an alpha coefficient of .95 for the Effectiveness factor for parents and teachers.

Responses to the 7 items that comprise the BIRS-Effectiveness factor provided information on how parents and teachers perceived changes in the target behaviors. Parents and teachers completed the revised BIRS in its entirety at the end of the formal consultation relationship (i.e., following the final CBC interview).

Second, Goal Attainment Scaling (GAS; Kiresuk, Smith, \& Cardillo, 1994) procedures provided a second assessment of parents' and teachers' subjective perceptions of efficacy through their ratings of the degree to which consultation goals were attained. Following consultation, parents and teachers reported the degree to which they believed consultation goals were met using a scale of -2 (situation got significantly worse) to +2 (goal completely met). To simplify interpretation of the original scale, scores were transformed to a linear scale of 1 to $5(1=$ situation got worse; $3=$ no progress made; 5 = goal completely met).

Excellent reviews of the reliability and validity of GAS procedures are available in Cardillo and Smith (1994) and Smith and Cardillo (1994), respectively. Studies that used a 5-point scale (similar to the approach used herein) reported interrater reliability indices between $r=.87$ (Kaplan \& Smith, 1977) and $r=.93$ (Schippits \& Baxter, 1978; cited in Cardillo \& Smith, 1994). Analyses of test-retest reliability yielded product moment correlations of $r=.84$ over a two to three week period (Woodward, Santa-Barbara, Levin, \& Epstein, 1978). There is also evidence of criterion-related (Jacobs \& Cytrynbaum, 1977) and construct validity (e.g., Johnson \& Greenberg, 1985).

Acceptability ratings. Parents' and teachers' acceptability of CBC was assessed on the Behavior Intervention Rating Scale-Revised (BIRS; Von Brock \& Elliott, 1987). Specifically, 15 items comprising the BIRS-Acceptability factor were used to assess consultee acceptability of CBC services. Sheridan, Eagle et al. (2001) reported alpha coefficients of .94 for teachers and .86 for parents on the Acceptability factor. 


\section{Procedures}

Consultation training. A criterion-based training model was utilized to prepare consultants to engage in structured behavioral consultation practice (Kratochwill, Sheridan, Carrington Rotto, \& Salmon, 1991). Specifically, consultants were part of a larger training and research project that prepared individuals to engage in consultation services with parents and teachers of students with disabilities who were being educated in general education classrooms.

Consultation training followed a model described by Sheridan, Salmon, Kratochwill, and Carrington Rotto (1992), involving a series of advanced consultation seminars, role plays, and field-based practice with direct supervision. All consultants demonstrated mastery of $\mathrm{CBC}$ objectives equaling or exceeding $85 \%$ prior to beginning field-based cases (assessed by supervisors and independent observers using structured CBC objective checklists; see Sheridan, Eagle et al., 2001).

CBC cases. Following demonstrated mastery of consultation procedures, consultants were assigned to schools for the purpose of providing consultation services to parents and teachers of students with disabilities or who were at risk. CBC procedures were implemented following referrals made to consultants by school psychologists, teachers, or support staff in respective schools. The CBC cases followed a four-stage model, including problem identification, problem analysis, treatment implementation, and treatment evaluation (for more information on $\mathrm{CBC}$ procedures, see Sheridan et al., 1996). Parents and teachers were involved as joint consultees in all cases, and meetings were held conjointly (with all participants present). Most cases included four structured meetings between consultants and consultees, reflecting standard interviews for problem identification (Conjoint Problem Identification Interview; CPII), problem analysis (Conjoint Problem Analysis Interview; CPAI), and treatment evaluation (Conjoint Treatment Evaluation Interview; CTEI), and often a follow-up meeting assessing the effectiveness of revisions to intervention plans (approximating a second CTEI).

For most consultants, the cases represented in this data set were their first or second CBC cases. All interviews were audiotaped to allow for supervision and transcribing. Cases were supervised by the first author or an advanced graduate student. Data for a total of $85.5 \%(n=106)$ of the 124 cases are reported. Integrity of the CBC process was assessed by independent observers who listened to $\mathrm{CBC}$ audiotapes and recorded the number of objectives met on structured checklists. For this sample, the average percentage of objectives met was $89 \%$ (range $=47-100 \%$; $S D=9.45)$.

\section{Analyses}

To address the first hypothesis, which concerned congruence, a Pearson correlation was computed between the CEF scores of parents and teachers. To explore the hypotheses concerning agreement, absolute difference scores between parent and teacher CEF 
scores were calculated. Pearson product correlations were then computed between the difference scores and the following outcomes: effect size, parent acceptability, teacher acceptability, parent-perceived efficacy, teacher-perceived efficacy, parent-perceived goal attainment, and teacher-perceived goal attainment.

\section{RESU LTS}

\section{Descriptive Statistics}

Table 2 displays the means and standard deviations of all individual variables (i.e., teacher CEF, parent CEF, average effect size, teacher BIRS-Effectiveness, parent BIRS-Effectiveness, teacher GAS, parent GAS, teacher BIRS-Acceptability, and parent BIRS-Acceptability). Also included is the average of the dyadic variable (i.e., absolute value of the difference between teacher CEF and parent CEF).

\section{Relationship between Parents' and Teachers' Perceptions of Helpfulness}

To address the question of congruence between parents' and teachers' perceptions of helpfulness, a Pearson correlation was computed between parents' and teachers' total scores on the CEF. The resulting correlation was negative and nonsignificant $(r[79]$ $=-.07 ; p=.54)$.

\section{Relationship between Parent and Teacher Congruence and 0 bjective Case 0 utcomes}

Correlations between parent and teacher agreement and effects sizes at home and school are listed in Table 3. All correlations were in the negative direction, but not sig-

TABLE 2. Means and Standard Deviations across Outcome Measures

\begin{tabular}{lc}
\hline Outcome Measure & Mean (Standard Deviation) \\
\hline Teacher CEF $^{1}$ & $74.89(8.31)$ \\
Parent CEF $^{\text {Average Effect Size }}$ & $73.72(11.07)$ \\
Teacher BIRS-Effectiveness $^{2}$ & $1.18(1.67)$ \\
Parent BIRS-Effectiveness $^{\text {Teacher GAS }}{ }^{3}$ & $4.01(1.21)$ \\
Parent GAS $_{\text {Teacher BIRS-Acceptability }}^{4}$ & $4.61(1.03)$ \\
Parent BIRS-Acceptability $^{4}$ & $4.21(.66)$ \\
Mean Absolute CEF Difference Scores & $4.35(.58)$ \\
\hline
\end{tabular}

${ }^{1} \mathrm{CEF}=$ Consultant Evaluation Form (Range $\left.=12-84\right)$

${ }^{2}$ BIRS-Effectiveness $=$ Behavioral Intervention Rating Scale - Effectiveness Factor $($ Range $=1-6$ )

${ }^{3} \mathrm{GAS}=$ Goal Attainment Scaling (Range $=1-5$ )

${ }^{4}$ BIRS-Acceptability $=$ Behavioral Intervention Rating Scale - Acceptability Factor $($ Range $=1-6)$ 


\section{CONGRUENCE AMONG CBC PARTICIPANTS}

TABLE 3. Correlations between Parent/Teacher Agreement ${ }^{1}$ and Objective and Subjective Outcome Data

\begin{tabular}{ll}
\hline Average Effect Size & -.09 \\
Teacher GAS & -.01 \\
Parent GAS & -.07 \\
& $-.24^{2}$ \\
Teacher Acceptability & $-.21^{2}$ \\
Parent Acceptability & -.12 \\
Teacher Effectiveness Rating & $-.26^{2}$ \\
Parent Effectiveness Rating & \\
& 'Agreement is the absolute difference between parents' and teachers' \\
scores on the CEF. & \\
${ }^{2}$ Significant at $p<.05$ (one-tailed).
\end{tabular}

nificantly so. Thus, although there seems to be a pattern suggestive of decreases in objective outcomes as differences in congruence increase, this finding failed to reach significance.

\section{Relationship between Teacher and Parent Agreement and Social Validity 0 ut- comes}

Social validity was measured in two ways. First, parents' and teachers' perceptions of efficacy were assessed using the BIRS-Effectiveness factor and GAS. Second, acceptability of the $\mathrm{CBC}$ process was assessed using the BIRS-Acceptability factor. The correlations between parent and teacher CEF difference scores and social validity outcomes were all in the negative direction (see Table 3). Of these, significant correlations were found between difference scores and teacher acceptability $(r[79]=-.24)$, parent acceptability $(r[78]=-.21)$, and parent effectiveness $(r[79]=-.26$; all $p \mathrm{~s}<.05)$. Thus, as differences between parents and teachers increase regarding the helpfulness of $\mathrm{CBC}$, the acceptability of the model decreases for both parties. For just parents, as differences among parents and teachers increase, perceptions of the efficacy of $\mathrm{CBC}$ decreases.

\section{DISCUSSIO N}

The findings of this descriptive study suggest that parents' and teachers' perspectives of the helpfulness of the consultant are not necessarily related to each other. This is not surprising because participants enter the relationship with diverse goals, perspectives, and expectations, and this may result in different perceptions of what is helpful. Indeed, the various perspectives of participants in home-school partnerships have been highlighted (Christenson \& Sheridan, 2001), and CBC provides a vehicle by which to acknowledge those directly.

Although different perspectives are inherent in interactions involving different con- 
stituencies, the degree to which participants in CBC agree on what is helpful has not been investigated heretofore. Based on the conclusions of Pianta and Walsh (1996) and findings from Hansen (1986), we hypothesized that as disagreement between parents and teachers increased, objective and subjective outcomes would decrease (i.e., there would be a negative relationship). This hypothesis was partly supported. Specifically, all correlations were in the negative direction. However, only correlations between difference scores and subjective outcomes (i.e., parent acceptability, teacher acceptability, parent effectiveness) were significant. Correlations between difference scores and effect sizes were close to zero. Thus, significant correlations concerned relationships between agreement and perceptions of consultees, but not between agreement and behavioral outcomes. This highlights the importance of measuring social validity outcomes, which appear to be based on factors that extend beyond mere discrete behavior change (Sheridan, Cowan et al., 2001).

The findings in this study are consistent with Erchul et al. (1992), who found that when consultees and consultants experience the consultation process similarly, understand their roles, and work together as a team, the outcomes are more favorable. According to these authors, teamwork assumes that each person has a clear expectation of his or her role as well as the role of the other person, and that all individuals actively participate in the process, but with the understanding that the nature of participation is certain to vary across individuals. Although the results of the present study perhaps are not as robust as those of Erchul et al., there is a basis on which to claim the construct of agreement and notion of teamwork have been extended successfully from traditional school-based consultation to home-school partnerships.

Unique to this study is the rather large sample for which $\mathrm{CBC}$ cases were completed. Objective and subjective data on the authentic, field-based cases were collected and logged over the course of five years. They represent naturalistic problem solving consultation cases referred in the context of actual school experiences, and follow a "best practices" approach to data-based decision making. Multi-source, multi-method, multisetting assessment strategies were used to evaluate case outcomes, and in most situations, subjective measures of outcomes corroborated behavioral data collected by parents and teachers. Although rigorous research designs with highly prescriptive measurement and analysis techniques were not employed, our current approach to field research included multiple elements that allowed us to draw meaningful inferences from our case data (Galloway \& Sheridan, 1994; Kratochwill, 1985).

The findings in this study suggest several implications for the practice of CBC. Parents and teachers appear to have different needs and expectations in the CBC interaction. In light of the importance of agreement related to what teachers and parents view as helpful, it may be important for consultants to spend time identifying these varied perspectives and expectations prior to initiating the problem solving agenda. Having information about unique or shared goals, desires, and needs helps elucidate the degree 
of congruence and agreement between parties a priori. This in turn can influence a consultant's efforts to strengthen congruence between participants, determine the direction of $\mathrm{CBC}$, and engage in behaviors that are mutually helpful for all participants. Congruence between parents and teachers can be enhanced through increased interactions over time, similar to those possible in CBC exchanges (Christenson \& Sheridan, 2001).

\section{Limitations of Research}

Findings of the present study must be considered in light of some noteworthy limitations. First, the objective behavioral data used to compute effect sizes in the single case studies were collected and reported by teachers and parents, with no assessment of reliability. As mentioned previously, the data used in this analysis were collected over a span of several years in two different geographic locations. Whereas the data are considered very authentic (i.e., collected in actual casework in home and school settings), their accuracy cannot be determined unequivocally. Consistent with "best practices" in case study design, clear operationalization of target concerns, consultee training in data collection, graphing of results, and debriefing were used to maximize reliability of the behavioral data. Nevertheless, future researchers should attempt to develop unobtrusive, cost-effective procedures for collecting objective, independent behavioral data across home and school settings in large-scale consultation research efforts. Until such strategies are identified, it is critical to continue to collect naturalistic behavioral data in ways that maximize the effective use of available resources, and capitalize on sound, data-based procedures.

A second limitation concerns two psychological measurement issues. First, it is acknowledged that use of a difference score (i.e., our basis for operationalizing agreement) results in lower reliability because it effectively magnifies the measurement error found in the individual variables (Cronbach, 1958; Schulte \& Borich, 1984). In other words, we duly note that a teacher/parent CEF difference score will contain more errors than either score alone. This phenomenon may explain why only three significant CEF difference score findings - all with social validity outcomes - were obtained and recognize that future investigators may find a somewhat different pattern of results. Second, no significant correlations were found for comparisons involving the CEF difference score and the parent and teacher GAS, perhaps due to the restricted range of the GAS (see Table 2). When a measure has limited variability, the odds of obtaining a significant correlation are lowered considerably. Additional ways to measure the constructs of agreement and congruence may yield different results and yield fruitful new directions for future research.

Third, the consultant sample used in this study is rather select. All consultants involved in this study were trained in a competency-based model, using rigorous procedures and criteria for mastery. Constant direct supervision was used to assist consul- 
tants in their development and casework. It is not known if their performance as consultants differs significantly from other consultants in the field, thus limiting the generalizability of the findings to other field-based consultants.

\section{Future Research Directions}

The results of the present study answered some preliminary questions, but opened the door for many avenues for future research. First, the limitations raised above should be addressed in an empirically and methodologically sound way. Second, it will be important to begin to understand more systematically the goals, needs, and expectations of consultees entering a $\mathrm{CBC}$ relationship. The development and validation of an instrument assessing such issues prior to the initiation of CBC may yield important clinical and research information.

Considering that consultants have a repertoire of skills from which to draw, it is necessary to begin examining specific procedures that promote or facilitate congruence between parents and teachers. Specifically, it would be helpful to assess directly the actions in which consultants engaged and determine their effects on the development of congruence among participants. There is a clear understanding of the necessary verbal behaviors used by consultants to guide the problem solving process toward problem resolution (Bergan \& Tombari, 1975; Fuchs, Fuchs, Bahr, Fernstrom, \& Stecker, 1990); however, researchers have not yet identified the critical skills that are necessary to aid in the development of constructive parent-teacher partnerships and facilitate cross-participant congruence. Such research can provide important directions for training future consultants and informing the practice of consultants in school settings.

An additional line of research is necessary to investigate the effects of increased congruence generated through CBC. Specifically, it would be helpful to ascertain if agreement in what consultees deem helpful may generalize to other aspects of the parent-teacher relationship. Longitudinal research that explores changes in the nature of the relationship, issues on which parents and teachers agree and disagree, and other relational characteristics of home-school partnerships will be useful (Christenson \& Anderson, 2002).

\section{REFEREN CES}

Bergan, J. R., \& Tombari, M. L. (1975). The analysis of verbal interactions occurring during consultation. Journal of School Psychology, 13, 209-226.

Bronfenbrenner, U. (1979). The ecology of human development. Cambridge, MA: Harvard University Press.

Busk, P. L., \& Serlin, R. C. (1992). Meta-analysis for single-case research. In T. R. Kratochwill \& J. R. Levin (Eds.), Single-case research design and analysis: Applications in psychology and education (pp. 187-212). Hillsdale, NJ: Lawrence Erlbaum Associates.

Cardillo, J. E., \& Smith, A. (1994). Reliability of goal attainment scores. In T. J. Kiresuk, A. Smith, \& J. E. Cardillo (Eds.) Goal attainment scaling: Applications, theory, and measurement (pp. 213-242). Hillsdale, NJ: Lawrence Erlbaum. 
Chavkin, N. F., \& Williams, D. L. (1988). Critical issues in teacher training for parent involvement. Educational Horizons, 66, 87-89.

Christenson, S. L., \& Anderson, A. R. (2002). Commentary: The centrality of the learning context for students' academic competence. School Psychology Review, 31, 378-393.

Christenson, S. L., \& Sheridan, S. M. (2001). Schools and families: Creating essential connections for learning. New York: Guilford Publications, Inc.

Colton, D. L. \& Sheridan, S. M. (1998). Conjoint behavioral consultation and social skills training: Enhancing the play behaviors of boys with attention deficit hyperactivity disorder. Journal of Educational and Psychological Consultation, 9, 3-28.

Comer, J. P. (1980). School power: Implications of an intervention project. New York: Free Press.

Cronbach, L. J. (1958). Proposals leading to analytic treatment of social perception scores. In R. Taguiri \& L. Petrullo (Eds.), Person perception and interpersonal behavior (pp. 353-379). Stanford, CA: Stanford University Press.

Dunst, C. J., \& Trivette, C. M. (1987). Enabling and empowering families: Conceptual and intervention issues. School Psychology Review, 16, 443-456.

Dunst, C. J., \& Trivette, C. M. (1994). What is effective helping? In C. J. Dunst, C. M. Trivette, \& A. G. Deal (Eds.), Supporting and strengthening families: Methods, strategies and practices (pp. 162-170). Cambridge, MA: Brookline Books.

Dunst, C. J., Trivette, C. M., Davis, M. \& Cornwell, J. C. (1994). Characteristics of effective help-giving practices. In C. J. Dunst, C. M. Trivette \& A. G. Deal (Eds.), Supporting and strengthening families: Methods, strategies and practices (pp. 171-186). Cambridge, MA: Brookline Books.

Dunst, C. J., Trivette, C. M., \& Deal, A. G. (1988). Enabling and empowering families: Principles and guidelines for practice. Cambridge, MA: Brookline Books.

Dunst, C. J., Trivette, C. M., \& Deal, A.G. (1994). Enabling and empowering families. In C. J. Dunst, C. M. Trivette, \& A. G. Deal (Eds.), Supporting and strengthening families. (pp. 1-11). Cambridge, MA: Brookline Books.

Elliott, S. N., \& Von Brock Treuting, M. (1991). The Behavior Intervention Rating Scale: Development and validation of a pretreatment acceptability and effectiveness measure. Journal of School Psychology, 29, $43-51$.

Erchul, W. P. (1987). A relational communication analysis of control in school consultation. Professional School Psychology, 2, 113-124.

Erchul, W. P., \& Chewning, T. G. (1990). Behavioral consultation from a request-centered relational communication perspective. School Psychology Quarterly, 5, 1-20.

Erchul, W. P., Covington, C. G., Hughes, J. N., \& Meyers, J. (1995). Further explorations of request-centered relational communication within school consultation. School Psychology Review, 24, 621-632.

Erchul, W. P., Hughes, J. N., Meyers, J., Hickman, J. A., \& Braden, J. P. (1992). Dyadic agreement concerning the consultation process and its relationship to outcome. Journal of Educational and Psychological Consultation, 3, 119-132.

Erchul, W. P., Raven, B. H., \& Whichard, S. M. (2001). School psychologist and teacher perceptions of social power bases in school consultation. Journal of School Psychology, 39, 483-497.

Erchul, W. P., Sheridan, S. M., Ryan, D. A., Grissom, P. F., Killough, C. E., \& Mettler, D. W. (1999). Patterns of relational communication in conjoint behavioral consultation. School Psychology Quarterly, 14, 121-147.

Freer, P., \& Watson, T. S. (1999). A comparison of parent and teacher acceptability ratings of behavioral and conjoint behavioral consultation. School Psychology Review, 28, 672-684. 
Fuchs, D., Fuchs, L. S., Bahr, M. W., Fernstrom, P., \& Stecker, P. M. (1990). Prereferral intervention: A prescriptive approach. Exceptional Children, 56, 493-513.

Galloway, J., \& Sheridan, S. M. (1994). Implementing scientific practices through case studies: Examples using home-school interventions and consultation. Journal of School Psychology, 32, 385-413.

Gutkin, T. B., \& Curtis, M. J. (1999). School-based consultation theory and practice: The art and science of indirect service delivery. In C. R. Reynolds \& T. B. Gutkin (Eds.), The handbook of school psychology (3rd ed., pp. 598-637). New York: Wiley.

Hansen, D. A. (1986). Family-school articulations: The effects of interaction rule mismatch. American Educational Research Journal, 23, 643-659.

Henderson, A. T. (1987). The evidence continues to grow: Parent involvement improves student achievement. Columbia, MD: National Committee for Citizens in Education.

Hill, N. E. (2001). Parenting and academic socialization as they relate to school readiness: The roles of ethnicity and family income. Journal of Educational Psychology, 93, 686-697.

Jacobs, S., \& Cytrynbaum, S. (1977). The goal attainment scale: A test of its use on an inpatient crisis intervention unit. Goal Attainment Review, 3, 77-98.

Johnson, S. M., \& Greenberg, L. S. (1985). Differential effects of experiential and problem-solving interventions in resolving marital conflict. Journal of Consulting and Clinical Psychology, 53, 175-184.

Kaplan, J. M., \& Smith, W. G. (1977). The use of attainment scaling in the evaluation of a regional mental health program. Community Mental Health Journal, 13, 188-193.

Kazdin, A. E. (1977). Assessing the clinical or applied significance of behavioral change through social validation. Behavior Modification, 1, 427-452.

Kiresuk, T. J., Smith, A., \& Cardillo, J. E. (Eds.). (1994). Goal attainment scaling: Applications, theory, and measurement. Hillsdale, NJ: Lawrence Erlbaum.

Kratochwill, T. R. (1985). Case study research in school psychology. School Psychology Review, 14, 204215.

Kratochwill, T. R., Sheridan, S. M., Carrington Rotto, P., \& Salmon, D. (1991). Preparation of school psychologists to serve as consultants for teachers of emotionally disturbed children. School Psychology Review, 20, 530-549.

Laing, R. D., Phillipson, H., \& Lee, A. R. (1966). Interpersonal perception: A theory and a method of research. New York: Springer.

McLeod, J. M., \& Chaffee, S. H. (1973). Interpersonal approaches to communication research. American Behavioral Scientist, 16, 469-499.

McWilliam, R. A., Maxwell, K. L., \& Sloper, K. M. (1999). Beyond involvement: Are elementary schools ready to be family-centered? School Psychology Review, 28, 378-394.

Miller, G. A. (1969). Psychology as a means of promoting human welfare. American Psychologist, 24, 10631075.

Phelan, P., Davidson, A. L., \& Yu, H. C. (1998). Adolescents'worlds: Negotiating family, peers, and school. New York: Teachers College Press.

Pianta, R., \& Walsh, D. B. (1996). High-risk children in schools: Constructing sustaining relationships. New York: Routledge.

Schippits, H., \& Baxter, J. W. (1978). Tightening the hitch: An update on "hitch your treatment to a goal." Paper presented at Adult Psychiatric Day Treatment: 2nd Multi-Disciplinary National Forum, Minneapolis, MN.

Schulte, A. C., \& Borich, G. D. (1984). Considerations in the use of difference scores to identify learning disabled children. Journal of School Psychology, 22, 381-390. 
Sheridan, S. M., Cowan, R. J., Warnes, E. D., Brown, M. S., Schemm, A. V., \& Marti, D. C. (2001, August). In the eye of the beholder: Assessing relationships among consultation outcomes. Paper presented at the annual conference of the American Psychological Association, San Francisco.

Sheridan, S. M., Eagle, J. W., Cowan, R. J., \& Mickelson, W. (2001). The effects of conjoint behavioral consultation: Results of a four-year investigation. Journal of School Psychology, 39, 361-385.

Sheridan, S. M., \& Kratochwill, T. R. (1992). Behavioral parent-teacher consultation: Conceptual and research considerations. Journal of School Psychology, 30, 117-139.

Sheridan, S. M., Kratochwill, T. R., \& Bergan, J. R. (1996). Conjoint behavioral consultation: A procedural manual. New York: Plenum Press.

Sheridan, S. M., Salmon, D., Kratochwill, T. R., \& Carrington Rotto, P. J. (1992). A conceptual model for the expansion of behavioral consultation training. Journal of Educational and Psychological Consultation, 3, 193-218.

Sheridan, S. M., \& Steck, M. C. (1995). Acceptability of conjoint behavioral consultation: A national survey of school psychologists. School Psychology Review, 24, 633-647.

Sheridan, S. M., Welch, M., \& Orme, S. F. (1996). Is consultation effective: A review of outcome research. Remedial and Special Education, 17, 341-354.

Smith, A., \& Cardillo, J. E. (1994). Perspectives on validity. In T. J. Kiresuk, A. Smith, \& J. E. Cardillo (Eds.) Goal attainment scaling: Applications, theory, and measurement (pp. 243-272). Hillsdale, NJ: Lawrence Erlbaum.

Von Brock, M., \& Elliott, S. N. (1987). Influence and treatment effectiveness information on the acceptability of classroom interventions. Journal of School Psychology, 25, 131-144.

Webster's II new Riverside dictionary (1984). New York: Berkley Publishing Company.

Weiner, R., Sheridan, S. M., \& Jenson, W. R. (1998). Effects of conjoint behavioral consultation and a structured homework program on math completion and accuracy in junior high students. School Psychology Quarterly, 13, 281-309.

Woodward, C. A., Santa-Barbara, J., Levin, S., \& Epstein, N. (1978). The role of Goal Attainment Scaling in evaluating family therapy outcome. American Journal of Orthopsychiatry, 48, 464-476.

The Action Editor for the journal-published version of this article was Melissa A. Bray.

Susan M. Sheridan, Ph.D., is a Willa Cather Professor and Professor of Educational Psychology at the University of Nebraska-Lincoln. Her primary research interests are in the areas of conjoint behavioral consultation, home-school partnerships, family engagement, and early intervention for children at risk. Dr. Sheridan is a past Lightner Witmer Award recipient and a Fellow of Division 16. She received her doctorate from the University of Wisconsin-Madison in 1989. The School Psychology Program at the University of NebraskaLincoln is accredited by the APA.

William P. Erchul, Ph.D., ABPP, is a Professor of Psychology and the Director of the School Psychology Program at North Carolina State University. His main research interest is interpersonal processes and outcomes associated with psychological consultation. Dr. Erchul is a past Lightner Witmer Award recipient and a Fellow of Division 16. He received his Ph.D. from the University of Texas at Austin in 1984. The School Psychology Program at North Carolina State University is accredited by the APA.

Melissa S. Brown, C.A.G.S., is a doctoral student in school psychology at the University of Nebraska-Lincoln. Her primary research interests include conjoint behavioral consultation, early childhood intervention, and home-school partnerships. 
Shannon E. Dowd, M.A., is an advanced graduate student in Educational Psychology at the University of Nebraska-Lincoln. She is the project director of a large federal grant in the area of conjoint behavioral consultation. Her research interests include home-school partnerships, social skills instruction, and school-based problem solving teams.

Emily D. Warnes, M.A., is a doctoral candidate in school psychology at the University of Nebraska-Lincoln. Her primary research interests include contextual and ecological approaches to social skills assessment and intervention with children, conjoint behavioral consultation, and home-school relationships.

Diane C. Marti, Ed.S., is a doctoral student in school psychology at the University of Nebraska-Lincoln. Her primary research interests include parent-child relationships, conjoint behavioral consultation and systemic interventions to improve child outcomes.

Ariadne V. Schemm, M.A., is an advanced school psychology doctoral student at the University of Nebraska-Lincoln. Her research interests include using conjoint behavioral consultation (CBC) as a tool in preventing student dropout and increasing student participation in academic team planning. Ms. Schemm received her Master of Arts degree in Developmental Disabilities at St. Mary's University in Minneapolis.

John W. Eagle, M.S.W., is a doctoral candidate in the Department of Educational Psychology at the University of Nebraska-Lincoln. His research interests include home-school partnerships, conjoint behavioral consultation, and school-based mental health. He was awarded an AERA/Spencer Pre-Dissertation Fellowship in 2002 for outstanding student achievement. He received his M.S.W. from the University of Michigan, in Ann Arbor. 